\title{
Effects of hyperbaric oxygen on intracranial pressure and cerebral blood flow in experimental cerebral oedema ${ }^{1}$
}

\author{
J. D. MILlER ${ }^{2}$, I. McA. LEDINGHAM, AND W. B. JENNETT \\ From the Hyperbaric Unit, University Department of Surgery, Western Infirmary, and the University \\ Department of Neurosurgery, Institute of Neurological Sciences, Glasgow.
}

SUMMARY Increased intracranial pressure was induced in anaesthetized dogs by application of liquid nitrogen to the dura mater. Intracranial pressure and cerebral blood flow were measured, together with arterial blood pressure and arterial and cerebral venous blood gases.

Carbon dioxide was administered intermittently to test the responsiveness of the cerebral circulation, and hyperbaric oxygen was delivered at intervals in a walk-in hyperbaric chamber, pressurized to two atmospheres absolute.

Hyperbaric oxygen caused a $30 \%$ reduction of intracranial pressure and a $19 \%$ reduction of cerebral blood flow in the absence of changes in arterial $\mathrm{PCO}_{2}$ or blood pressure, but only as long as administration of carbon dioxide caused an increase in both intracranial pressure and cerebral blood flow. When carbon dioxide failed to influence intracranial pressure or cerebral blood flow then hyperbaric oxygen had no effect. This unresponsive state was reached at high levels of intracranial pressure.

Brain swelling and increased intracranial pressure (ICP) complicating certain types of head injury, brain tumour, or cerebrovascular lesion present a continuing challenge to the neurosurgeon. Despite the significant advances in treatment provided by hypertonic solutions, hypothermia, steroids, and hyperventilation, the search continues for further non-operative measures in the treatment of brain swelling.

Hyperbaric oxygen (OHP) has been proposed as a form of treatment in such states of increased ICP. Evidence for the efficacy of OHP in this role has come mainly from studies in experimental animals, in which OHP has been shown to reduce the mortality from cerebral oedema and compression (Coe and Hayes, 1966; Dunn and Connolly, 1966; Sukoff, Hollin, Espinosa, and Jacobson, 1968; Moody, Mead, Ruamsuke, and Mullan, 1970). Clinical studies in patients with cerebral lesions associated with brain swelling and increased ICP have so far yielded widely varying and inconclusive

'This work has been supported by the Medical Research Council. J.D.M. was in receipt of a Medical Research Council Fellowship. 'Present address: Division of Neurosurgery, Hospital of the University of Pennsylvania, Philadelphia, PA 19104, U.S.A. results (Hayman et al., 1966; Fasano, Broggi, Urcinoli, De Nunno, and Lombard, 1966; Wüllenweber, Gott, and Holbach, 1969; Megami, Hayakawa, Kanai, Kuroda, Yamada, Ikeda, Katsurada, and Sugimoto, 1969). At the present time no properly controlled trial of OHP in the treatment of such patients has been reported, and in addition, little information exists as to the physiological actions of OHP in the presence of increased ICP.

In a previous study we have investigated the action of OHP on increased ICP, produced by the inflation of extradural balloons in anaesthetized, ventilated dogs (Miller, Fitch, Ledingham, and Jennett, 1970). The administration of OHP was associated with a rapid and significant fall of ICP (mean $37 \%$ ), occurring in the absence of changes of arterial blood pressure (BP) or carbon dioxide tension $\left(\mathrm{PCO}_{2}\right)$. This effect persisted only during the administration of OHP, and ICP rose again as soon as air breathing was resumed. The reduction of ICP by OHP was observed only when cerebral vessels were able to respond to an increased arterial $\mathrm{PCO}_{2}$ by vasodilatation and increased ICP; when the response to carbon dioxide was lost, at high levels of ICP, OHP no longer reduced ICP. 
The present study was designed to simulate more closely the states of cerebral oedema and raised ICP encountered in clinical neurosurgical practice, as it is in such situations that OHP therapy might be expected to have a place. For this purpose, liquid nitrogen was applied to the intact dura mater through a burrhole. This produces a swollen, haemorrhagic cerebral lesion, similar to a cerebral contusion associated with raised intracranial pressure (Rosomoff, 1959). The changes in ICP and cerebral blood flow over the succeeding six hours were observed, and the effect on these parameters of the administration of OHP. In one group of dogs (series A) changes in total cerebral blood flow (CBF) were derived from the cerebral arteriovenous oxygen content difference $\left(\mathrm{Ca}-\mathrm{vO}_{2}\right)$, and in another group (series $\mathrm{B}$ ) direct measurements of regional cerebral cortical blood flow (rCBF) were made by the krypton-85 beta clearance technique (Lassen and Ingvar, 1961 ; Harper, Glass, and Glover, 1961), using modifications described by Betz, Ingvar, Lassen, and Schmahl (1966) and Miller, Fitch, and Cameron (1969).

\section{MATERIALS AND METHODS}

Fifteen unselected mongrel dogs, weighing between 12 and $35 \mathrm{~kg}$, were anaesthetized by intravenous sodium thiopentone $(20 \mathrm{mg} / \mathrm{kg})$, intubated, and artificially ventilated using a modified Starling pump. Suxamethonium was administered by intramuscular injection $(25 \mathrm{mg})$ at intervals. Anaesthesia was maintained with trichlorethylene ( 0.7 to $1.1 \%)$ carried in a mixture of oxygen and nitrogen, or in pure oxygen.

End-expiratory carbon dioxide concentration $\left(\mathrm{FECO}_{2}\right)$ was measured continuously by infra-red analyzer (Hartmann and Braun, URAS 4) and the percentage of inspired oxygen measured intermittently by paramagnetic oxygen analyzer (Servomex 101). The stroke volume of the Starling pump was adjusted to keep arterial $\mathbf{P C O}_{2}$ close to $40 \mathrm{mmHg}$, and the $\mathrm{FIO}_{2}$ adjusted to hold arterial oxygen tension $\left(\mathrm{PO}_{2}\right)$ near to $100 \mathrm{mmHg}$.

The experiments were all carried out in a walk-in hyperbaric chamber at an ambient pressure of two atmospheres absolute (2ATA) (Table 1). The $\mathrm{FIO}_{2}$ of the oxygen : nitrogen mixture required to yield an arterial $\mathrm{PO}_{2}$ of $100 \mathrm{mmHg}$ was therefore about $10 \%$, and this is referred to as air-equivalent. When the dogs breathed

TABLE 1

HYPERBARIC TERMINOLOGY - PRESSURE EQUIVALENTS

\begin{tabular}{ccccc}
\hline $\begin{array}{c}\text { Atmospheres } \\
\text { absolute }\end{array}$ & $\begin{array}{c}\text { Gauge } \\
\text { pressure } \\
\text { (psig) }\end{array}$ & $\begin{array}{c}\text { Barometric } \\
\text { pressure } \\
(\mathrm{mmHg})\end{array}$ & $\begin{array}{c}\text { Sea water } \\
(\mathrm{ft})\end{array}$ & $\begin{array}{c}\text { Sea water } \\
(\mathrm{m})\end{array}$ \\
\hline 1 & 0 & 760 & 0 & 0 \\
2 & $14 \cdot 7$ & 1,520 & 33 & 10 \\
3 & $29 \cdot 4$ & 2,280 & 66 & 20 \\
\hline
\end{tabular}

$100 \%$ oxygen at $2 \mathrm{ATA}(\mathrm{OHP})$, arterial $\mathrm{PO}_{2}$ rose rapidly from 100 to over $1,000 \mathrm{mmHg}$. Since the amount of oxygen carried in physical solution in the arterial blood is directly related to the $\mathrm{PO}_{2}$, this increased the dissolved oxygen content from 0.3 to c. $3.0 \mathrm{ml} . / 100 \mathrm{ml}$, an increase of $15 \%$ in total arterial blood oxygen content.

SERIES A Surgical preparation The temporal muscles were stripped from the calvarium and two $\frac{1}{2}$ in. diameter trephine openings made, one over the left parietal eminence, the other in the midline, exposing the sagittal sinus; the dura mater was left intact. The midline opening was enlarged to deroof the sinus and the diploic channels sealed with bone wax; the sinus was entered with a fine-bore cannula, passed posteriorly to the bony portion of the sinus. Cerebral venous blood was slowly withdrawn at intervals for immediate measurement of $\mathrm{pH}, \mathrm{PCO}_{2}$, and $\mathrm{PO}_{2}$.

A copper cylinder 3 in. long, with a brass end-plate $0.5 \mathrm{in}$. diameter was inserted into the left parietal opening, using electrode jelly on the base plate to ensure an air-free contact with the dura mater. Liquid nitrogen was then poured into the cylinder for 10 minutes exactly; the resulting lesion is shown in Fig. 1. When thawing was complete, a hollow, tapered screw was impacted into the burrhole, filled with saline, and connected to a pressure transducer (Elema-Schönander EMT 34) and a multi-o channel ink-jet chart recorder (Elema-Schönandeक्ष 0 of Mingograf 81). The ICP was thus recorded from the extradural space directly overlying the cryogenic braip lesion.

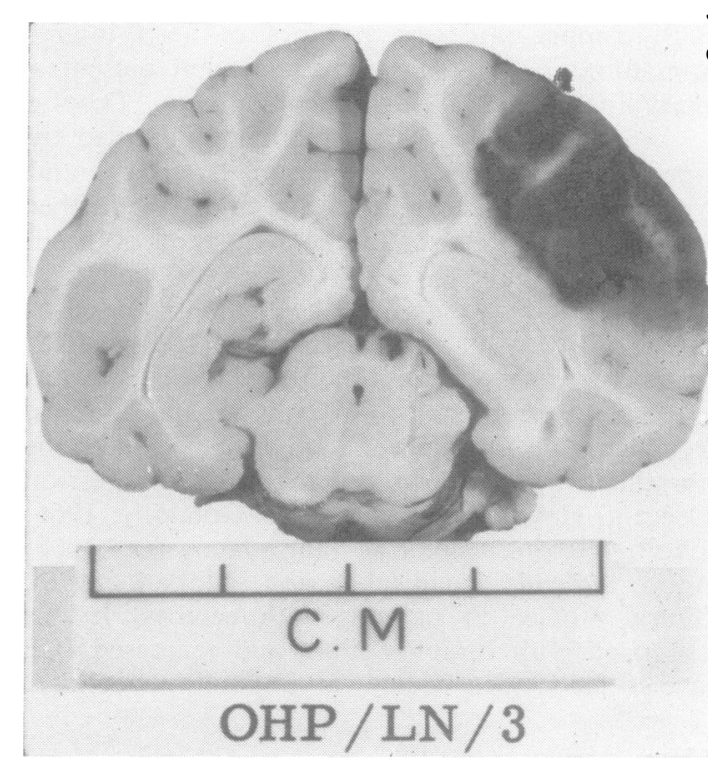

FIG. 1. Coronal section of dog brain showing the lesion produced by application of liquid nitrogen to the intact dura for 10 minutes six hours previously. Note the swelling of the hemisphere. 
The aorta and inferior vena cava were cannulated from the femoral artery and vein, and arterial blood pressure and central venous pressure monitored continuously using pressure transducers and the chart recorder. Arterial blood was withdrawn at intervals into capped, heparinized $2 \mathrm{ml}$. syringes for immediate blood gas measurement.

BLOOD GAS MEASUREMENTS The measurements of arterial and cerebral venous $\mathrm{pH}, \mathrm{PCO}_{2}$, and $\mathrm{PO}_{2}$ were made using direct-reading electrodes (Radiometer E5021, E5034, E5046), which were operated within the hyperbaric chamber, and there calibrated against solutions of known $\mathrm{pH}$ and gases of known carbon dioxide and oxygen content; the blood-gas difference for the oxygen electrode was determined for each experiment using the Torres rotating syringe tonometer and the appropriate correction made to the $\mathrm{PO}_{2}$ values (McDowall, Ledingham, and Tindal, 1968). Further corrections were made to all three values for any difference between the rectal temperature of the dog and the electrode system in excess of $0.5^{\circ} \mathrm{C}$, using the Radiometer Blood Gas Calculator (Severinghaus, 1966).

Blood oxygen saturation $\left(\mathrm{SO}_{2}\right)$ was derived from the $\mathrm{PO}_{2}$ values, using the Radiometer Blood Gas Calculator, which takes account of $\mathrm{pH}$, temperature, and base excess (Severinghaus, 1966). These derived values were checked at random against direct measurements on an oxygen saturation meter (Radiometer: OSM1) and close correspondence found.

In the course of each experiment, three or four measurements of arterial blood haemoglobin concentration were made using $\mathrm{KCN}$ and a standard spectrophotometric technique. The total oxygen content $\left(\mathrm{CO}_{2}\right)$ of arterial and cerebral venous blood was obtained from the following equation:

$$
\begin{aligned}
\mathrm{CO}_{2}(\mathrm{ml} . / 100 \mathrm{ml} .)= & \mathrm{Hb}(\mathrm{g} / 100 \mathrm{ml} .) \times 1.34 \times \\
& \mathrm{SO}_{2}(\%)=0.003 \times \mathrm{PO}_{2}(\mathrm{mmHg})
\end{aligned}
$$

The derived values of $\mathrm{CO}_{2}$ were also checked at random against direct measurements made using the van Slyke manometric technique. Cerebral arteriovenous oxygen content difference $\left(\mathrm{Ca}-\mathrm{VO}_{2}\right)$ was obtained by subtraction.

SERIES B $\quad r C B F$ measurement The right carotid artery was exposed and its thyroid branch cannulated for injection of krypton-85 solution. A one inch trephine opening was made over the right parietal eminence, dura mater left intact, apart from light coagulation of dural vessels around the margins of the bone defect. Lead shielding with a $7 \mathrm{~mm}$ central aperture was placed over the dura, so that the aperture lay over a gyrus, now visible through the devascularized dura (Fig. 2). An end-window Geiger-Muller tube (Mullard MX113) was placed over the aperture in the lead shield, as close to the dura as possible. The impulses from the tube were directed both to a scaler/timer (IDL 7000) to record total counts of beta radiation over a preset time interval, and to a linear ratemeter (IDL 7070) set at a time constant of one second and a range of 400 or 1,000 counts per second. A potentiometric chart recorder (Goertz Servoscribe) connected to the ratemeter, permitted display of the clearance curve of beta radiation.

To measure $\mathrm{rCBF}$, a bolus injection of $0.5-1.0 \mathrm{ml}$. saline, containing $0.5-1.0 \mathrm{mC}$ krypton-85, warmed to body temperature, was made into the carotid artery. The resulting clearance curve of beta radiation was analysed by the stochastic method to yield mean flow over a 10 minute period (Zierler, 1965).

$\begin{aligned} \mathrm{rCBF} & (\mathrm{ml} . / \mathrm{g} / \mathrm{min})=\lambda \times \frac{\mathrm{H}-\mathrm{H} 10}{\mathrm{~A} 10-\mathrm{B}} \text { where } \\ \lambda & =\text { partition coefficient for } 85 \mathrm{Kr} \text { between blood and } \\ & \text { cortex } \\ \mathrm{H} & =\text { maximum count rate from the clearance curve } \\ \mathrm{H} 10 & =\text { count rate after } 10 \text { minutes } \\ \mathrm{A} 10= & \text { total counts over } 10 \text { minutes, from scaler-that } \\ & \text { is, area under curve } \\ \mathrm{B}= & \text { background count over } 10 \text { minutes (extrapolated) }\end{aligned}$
FIG. 2. Diagram to show the method of measurement of intracranial pressure from the extradural space overlying the cryogenic lesion, and regional cerebral blood flow from the opposite hemisphere (Series B). 
The figure used for the partition coefficient was 0.91 ; this has been obtained by direct measurement in the cerebral cortex of the dog by Glass and Harper (1962).

Other measurements The sagittal sinus was cannulated, but in this group of dogs the cannula was passed forwards, so that the tip lay opposite the area of cortex in which rCBF was measured. The cryogenic lesion was made in the left cerebral hemisphere and ICP measured as described, but using a slow-running heated stylus chart recorder (Devices M2). Arterial blood pressure and blood gas measurements were carried out.

EXPERIMENTAL PROTOCOL Series $A$ During surgical preparation and the production of the cryogenic brain lesion the dogs breathed air equivalent initially at normal atmospheric pressure, then at 2 ATA. When a steady level of increased ICP had been attained, ICP and BP were recorded over 10 minutes and the mean value obtained; the inspired gases were then changed to $100 \%$ oxygen at 2 ATA for 15 to 30 minutes while monitoring of ICP and BP continued. Arterial and cerebral venous blood gases were measured during both air and oxygen breathing. Finally inspired gases were changed back to air equivalent and ICP and BP mean values obtained after a further five minutes. This sequence of events is referred to as a 'run'.

Series $B$ In these dogs three measurements of rCBF were made during air breathing, then a further three measurements during OHP. The rCBF values given in the results are the mean of each set of three measurements. Because of the time required for rCBF measurement, OHP was administered for longer periods in each run (40-60 min).

The statistical significance, in both series of animals, of changes associated with OHP administration was assessed using the paired $t$-test.

\section{RESULTS}

SERIES A Application of liquid nitrogen to the intact dura mater produced a rapid elevation of ICP in every dog (range 22 to $95 \mathrm{mmHg}$ ). Before the administration of OHP, $5 \%$ carbon dioxide was added to the inspired gases; in seven dogs there was a sharp increase in ICP (Table 2), but in the remaining dog, which had the highest ICP $(95 \mathrm{mmHg})$, no change in ICP was observed, despite an increase in arterial $\mathrm{PCO}_{2}$ from 39 to $76 \mathrm{mmHg}$.

In the seven dogs which responded to carbon dioxide, 25 runs of OHP were carried out. In every run the rise in arterial $\mathbf{P O}_{2}$ was associated with a rapid fall of ICP (mean reduction $35 \%$ ); on resumption of air breathing ICP rose rapidly to its former level (Fig. 3). There was no significant difference in the mean levels on air breathing before and after OHP, indicating the stability of this preparation in terms of raised ICP.

In the remaining dog, which failed to respond to
TABLE 2 SERIES A

EFFECT OF ADMINISTRATION OF CARBON DIOXIDE ON INTRACRANIAL PRESSURE, ARTERIAL BLOOD PRESSURE, AND ARTERIAL $\mathrm{PCO}_{2}$, TO SHOW THE INCREASE IN INTRACRANIAL PRESSURE PRODUCED IN RESPONSIVE STAGE

\begin{tabular}{|c|c|c|c|c|c|c|c|}
\hline \multirow{2}{*}{$\begin{array}{l}\text { Dog } \\
\text { no. }\end{array}$} & \multirow{2}{*}{$\begin{array}{c}\text { Run } \\
\text { no. }\end{array}$} & \multicolumn{2}{|c|}{$I C P(m m H g)$} & \multicolumn{2}{|c|}{$\mathrm{PaCO}_{2}(\mathrm{mmHg})$} & \multicolumn{2}{|c|}{$B P(m m H g)$} \\
\hline & & Control & $\mathrm{CO}_{2}$ & Control & $\mathrm{CO}_{2}$ & Control & $\mathrm{CO}_{2}$ \\
\hline \multirow[t]{2}{*}{1} & 1 & 37 & 42 & $39 \cdot 0$ & $81 \cdot 0$ & 115 & 100 \\
\hline & 2 & 43 & 50 & 37.5 & 95.0 & 115 & 105 \\
\hline 2 & 3 & 40 & 54 & 42.0 & $76 \cdot 0$ & 120 & 90 \\
\hline 3 & 4 & 20 & 42 & 40.0 & 68.0 & 90 & 95 \\
\hline 4 & 5 & 30 & 50 & $41 \cdot 5$ & $54 \cdot 5$ & 115 & 130 \\
\hline 5 & 6 & 60 & 74 & 39.0 & 61.0 & 120 & 120 \\
\hline \multirow[t]{2}{*}{6} & 7 & 20 & 30 & 40.5 & $48 \cdot 0$ & 110 & 115 \\
\hline & 8 & 20 & 30 & $31 \cdot 0$ & $40 \cdot 5$ & 80 & 100 \\
\hline 7 & 9 & 55 & 70 & $37 \cdot 8$ & $72 \cdot 0$ & 120 & 120 \\
\hline \multirow{2}{*}{\multicolumn{2}{|c|}{$\begin{array}{l}\text { Mean } \\
\text { S.E. }\end{array}$}} & $36 \cdot 0$ & $49 \cdot 1^{*}$ & $38 \cdot 7$ & $66 \cdot 2 *$ & $109 \cdot 4$ & $108 \cdot 3$ \\
\hline & & $5 \cdot 0$ & 4.9 & $1 \cdot 1$ & $5 \cdot 7$ & $4 \cdot 8$ & 4.5 \\
\hline
\end{tabular}

$* \mathbf{P}<0.001$

carbon dioxide by an increase in ICP, OHP (three runs) produced no change in ICP.

There was no significant difference in the levels of arterial BP or $\mathbf{P C O}_{2}$ during air and OHP, thus of

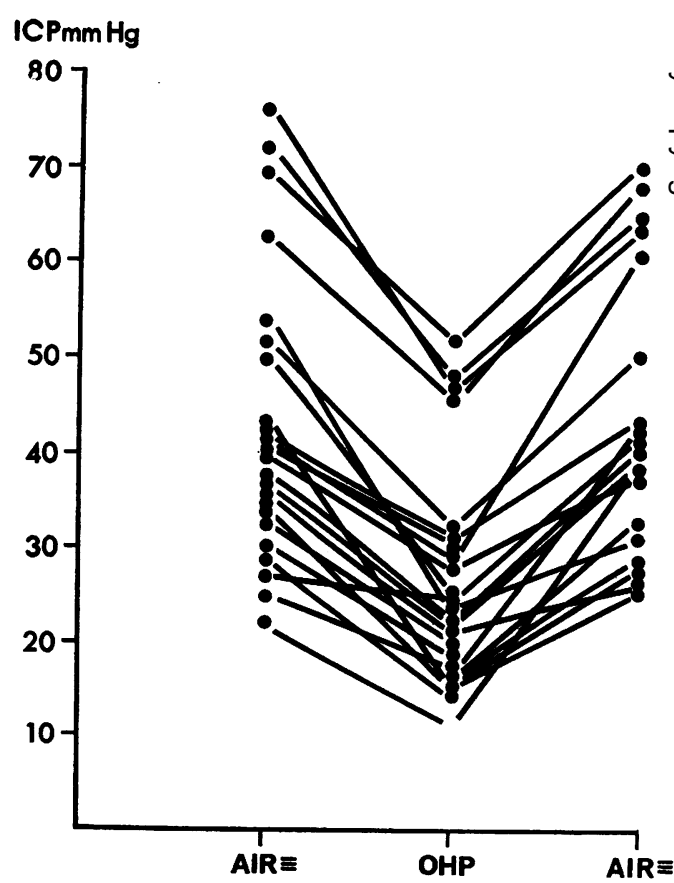

FIG. 3. Series A: reduction of intracranial pressure with administration of hyperbaric oxygen from values on air $\sigma$ equivalent both before and after OHP. (Liquid nitrogen $N$ lesion: 25 runs in seven dogs.) 
eliminating the possibility that the changes in ICP that were seen with OHP had been mediated by alterations in either of these factors (Table 3).

While there was an 11-fold rise in mean arterial $\mathrm{PO}_{2}$ with the change from air equivalent to OHP, cerebral venous $\mathrm{PO}_{2}$ doubled, from a mean value of $51 \pm 6 \mathrm{mmHg}$ on air equivalent to $119 \pm 11 \mathrm{mmHg}$ on OHP. Cerebral arteriovenous oxygen content differences were low throughout the study, but there was a significant increase in $\mathrm{Ca}-\mathrm{vO}_{2}$ with the administration of OHP. Cerebral arteriovenous $\mathrm{PCO}_{2}$ differences also increased significantly with OHP (Table 3).

Since the cerebral metabolic rate for oxygen is derived from the product of cerebral blood flow and $\mathrm{Ca}-\mathrm{vO}_{2}$, if it is assumed that the metabolic rate does not change with the administration of OHP, then relative changes in CBF may be calculated from the ratio of $\mathrm{Ca} \cdot \mathrm{vO}_{2}$ values during air and oxygen breathing. By this calculation, the increase in $\mathrm{Ca}-\mathrm{VO}_{2}$ during OHP administration was equivalent to a reduction of $19.5 \%$ in total cerebral blood flow.

SERIES B After the cryogenic lesion, ICP was increased in all seven animals (range 26 to 84 $\mathrm{mmHg}$ ). Five dogs responded to $5 \%$ carbon dioxide by an increase in ICP and in rCBF, but the two dogs with the highest ICP ( 80 and $84 \mathrm{mmHg}$ ) failed to show any alteration of ICP or rCBF despite marked elevation of arterial $\mathrm{PCO}_{2}$.

OHP reduced ICP in every run in the dogs which responded to carbon dioxide (Table 4); the mean reduction was $30 \%$, less than in series $A$ in which OHP was given for shorter periods. The effect of OHP was almost immediate, with an equally rapid return to, or in some instances above, the starting pressure on resumption of air breathing (Fig. 4). There was no significant change in arterial BP or $\mathrm{PCO}_{2}$ with the alteration of arterial $\mathrm{PO}_{2}$ (Table 4).

After the cryogenic brain lesion had been produced, $\mathrm{rCBF}$ values on air breathing varied widely (range 0.54 to $1.79 \mathrm{ml} / \mathrm{g} / \mathrm{min}$ ) in the dogs which responded to carbon dioxide, and were much lower in the two dogs which failed to respond $(0 \cdot 18$ and $0.20 \mathrm{ml} . / \mathrm{g} / \mathrm{min}$ ). In these latter two dogs OHP did not influence ICP or rCBF, whereas in the responsive dogs, in association with the reduction in ICP, there was a consistent fall in rCBF from $0.94 \pm 0.13$ to $0.76 \pm 0.11 \mathrm{ml} . / \mathrm{g} / \mathrm{min}$ ) a mean reduction of $19 \%$.

Since arterial BP was not altered, and ICP was significantly reduced, there was a significant increase in the cerebral perfusion pressure (BP-ICP:

TABLE 3 SERIES A

EFFECT OF ADMINISTRATION OF HYPERBARIC OXYGEN AT 2ATA ON INTRACRANIAL PRESSURE, ARTERIAL BLOOD PRESSURE, PCO, AND $P_{2}$, CEREBRAL VENOUS $\mathrm{PO}_{2}$ AND CEREBRAL ARTERIOVENOUS OXYGEN CONTENT AND PCO $_{2}$ DIFFERENCES

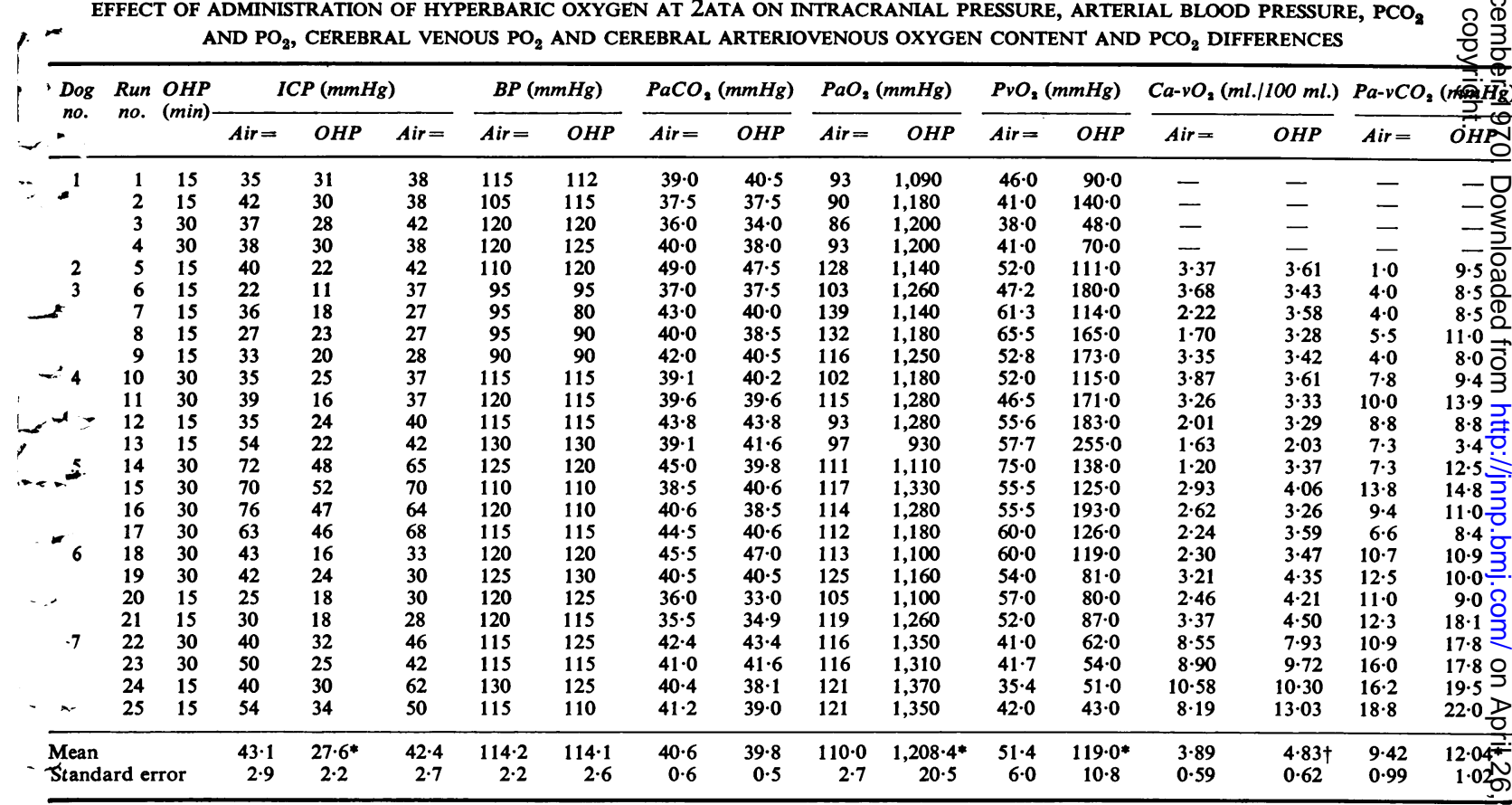

$=P<0.001+=P<0.005$ 
T A BLE 4 SERIES B

EFFECT OF HYPERBARIC OXYGEN AT 2ATA ON INTRACRANIAL PRESSURE, ARTERIAL BLOOD PRESSURE, PCO $_{2}$, AND PO ${ }_{2}$ REGIONAL $^{2}$ CEREBRAL BLOOD FLOW, CEREBRAL PERFUSION PRESSURE, CEREBROVASCULAR RESISTANCE, CEREBRAL VENOUS PO ${ }_{2}$, AND CEREBRAL ARTERIOVENOUS OXYGEN CONTENT AND PCO ${ }_{2}$ DIFFERENCES

\begin{tabular}{|c|c|c|c|c|c|c|c|c|c|c|c|c|c|c|c|c|c|c|c|c|c|c|}
\hline \multirow[t]{2}{*}{$\begin{array}{l}\text { Dog } \\
\text { no. }\end{array}$} & \multirow[t]{2}{*}{$\begin{array}{l}\text { Run } \\
\text { no. }\end{array}$} & \multirow[t]{2}{*}{$\begin{array}{c}O H P \\
(\min )\end{array}$} & \multicolumn{2}{|c|}{$\begin{array}{c}I C P \\
(m m H g)\end{array}$} & \multicolumn{2}{|c|}{$\begin{array}{c}B P \\
(m: n H g)\end{array}$} & \multicolumn{2}{|c|}{$\begin{array}{c}\mathrm{PaCO}_{2} \\
(\mathrm{mmHg})\end{array}$} & \multicolumn{2}{|c|}{$\begin{array}{c}\mathrm{PaO}_{2} \\
(\mathrm{mmHg})\end{array}$} & \multicolumn{2}{|c|}{$\begin{array}{c}r C B F \\
(m l . g / m i n)\end{array}$} & \multicolumn{2}{|c|}{$\begin{array}{c}C P P \\
(m m H g)\end{array}$} & \multicolumn{2}{|c|}{$\begin{array}{c}r C V R \\
(m m H g / \\
m l .100 g / m i n)\end{array}$} & \multicolumn{2}{|c|}{$\begin{array}{c}\mathrm{PvO}_{2} \\
(\mathrm{mmHg})\end{array}$} & \multicolumn{2}{|c|}{$\begin{array}{c}\mathrm{Ca}-v \mathrm{O}_{2} \\
(\mathrm{ml} . / 100 \mathrm{ml} .)\end{array}$} & \multicolumn{2}{|c|}{ 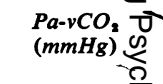 } \\
\hline & & & $A i r=$ & $O H P$ & $A i r=$ & $O H P$ & $A i r=$ & $O H P$ & $A i r=$ & $O H P$ & $A i r=$ & $O H P$ & Air $=$ & $O H P$ & $A i r=$ & $O H P$ & $A i r=$ & $O H P$ & $A i r=$ & $O H P$ & Air $=$ & $O H$ \\
\hline 1 & 1 & 40 & 45 & 31 & 125 & 120 & $44 \cdot 0$ & $45 \cdot 0$ & 98 & 1,020 & $1 \cdot 79$ & $1 \cdot 31$ & 80 & 89 & 0.45 & 0.68 & $44 \cdot 0$ & $52 \cdot 0$ & $5 \cdot 1$ & 6.9 & $7 \cdot 0$ & \\
\hline 1 & 2 & 50 & 37 & 28 & 130 & 122 & 42.0 & $42 \cdot 0$ & 124 & 1,080 & $1 \cdot 31$ & $1 \cdot 18$ & 93 & 94 & 0.71 & 0.80 & 30.0 & $45 \cdot 0$ & $10 \cdot 7$ & $8 \cdot 4$ & $18 \cdot 0$ & \\
\hline & 3 & 45 & 42 & 31 & 137 & 135 & 40.0 & 41.0 & 86 & 1,140 & $1 \cdot 31$ & $1 \cdot 15$ & 95 & 104 & 0.72 & 0.90 & 30.0 & $48 \cdot 0$ & $10 \cdot 2$ & 8.0 & $18 \cdot 0$ & 19.8 \\
\hline 2 & 4 & 50 & 64 & 59 & 110 & 110 & 42.0 & $42 \cdot 0$ & 89 & 1,140 & 0.58 & 0.46 & 46 & 51 & 0.79 & $1 \cdot 11$ & 46.0 & 116.0 & $4 \cdot 2$ & 3.6 & 8.0 & $12=0$ \\
\hline & 5 & 45 & 62 & 42 & 122 & 118 & $42 \cdot 5$ & 40.0 & 96 & 1,140 & 0.57 & 0.47 & 60 & 76 & 1.05 & 1.62 & $49 \cdot 0$ & 61.0 & $3 \cdot 8$ & $5 \cdot 7$ & 6.5 & 14 . \\
\hline & 6 & 45 & 59 & 52 & 127 & 122 & $42 \cdot 0$ & $42 \cdot 0$ & 90 & 1,120 & 0.54 & 0.50 & 68 & 70 & $1 \cdot 26$ & 1.40 & 45.0 & 66.0 & $4 \cdot 4$ & $5 \cdot 4$ & 10.0 & \\
\hline 3 & 7 & 50 & 26 & 19 & 112 & 108 & $38 \cdot 7$ & $38 \cdot 0$ & 112 & 1,200 & 0.75 & 0.62 & 86 & 89 & $1 \cdot 15$ & 1.43 & $58 \cdot 0$ & $122 \cdot 0$ & 3.4 & $4 \cdot 0$ & 10.9 & 11 . \\
\hline & 8 & 45 & 49 & 27 & 115 & 115 & $41 \cdot 2$ & $41 \cdot 2$ & 112 & 1,260 & 0.81 & 0.77 & 66 & 88 & 0.81 & $1 \cdot 14$ & 59.0 & $85 \cdot 0$ & $3 \cdot 5$ & 5.0 & 10.0 & \\
\hline & 9 & 50 & 46 & 33 & 110 & 106 & $41 \cdot 2$ & $41 \cdot 8$ & 103 & 1,320 & 0.79 & 0.72 & 64 & 73 & 0.81 & 1.01 & $55 \cdot 0$ & 87.0 & $4 \cdot 0$ & $5 \cdot 5$ & $11 \cdot 3$ & 15. \\
\hline 6 & 10 & 55 & 27 & 15 & 122 & 119 & $39 \cdot 5$ & $41 \cdot 6$ & 102 & 1,350 & 1.65 & $1 \cdot 23$ & 95 & 104 & 0.58 & 0.85 & $52 \cdot 0$ & 93.0 & $4 \cdot 7$ & 5.0 & $10 \cdot 1$ & 14. \\
\hline & 11 & 45 & 30 & 19 & 114 & 115 & $39 \cdot 0$ & $36 \cdot 7$ & 108 & 1,260 & 0.58 & 0.37 & 84 & 96 & 1.45 & 2.60 & 44.0 & $140 \cdot 0$ & $4 \cdot 6$ & 3.9 & $11 \cdot 5$ & 12.3 \\
\hline 7 & 12 & 60 & 29 & 10 & 105 & 108 & 37.0 & $34 \cdot 2$ & 106 & 1,320 & 0.62 & $0 \cdot 34$ & 76 & 998 & $1 \cdot 22$ & $2 \cdot 88$ & $57 \cdot 5$ & $62 \cdot 2$ & $4 \cdot 1$ & $7 \cdot 4$ & 10.0 & \\
\hline \multirow{2}{*}{\multicolumn{3}{|c|}{$\begin{array}{l}\text { Mean } \\
\text { Standard error }\end{array}$}} & 43 & $30 *$ & 119 & 116 & $40 \cdot 5$ & $40 \cdot 4$ & 105 & $1,196^{*}$ & 0.94 & $0.76^{*}$ & 76 & $86^{*}$ & 0.91 & $1 \cdot 29 t$ & $47 \cdot 4$ & $81 \cdot 4^{*}$ & $5 \cdot 2$ & $5 \cdot 7$ & $10 \cdot 9$ & \\
\hline & & & 4 & 4 & 3 & 2 & $1 \cdot 1$ & 0.8 & 4 & 29 & 0.13 & 0.11 & 4 & 5 & 0.09 & 0.23 & $2 \cdot 8$ & 9.0 & 0.7 & 0.5 & $1 \cdot 1$ & \\
\hline
\end{tabular}

$*=P<0.001 \quad \dagger=P<0.01 \quad \ddagger P<0.05$

Zwetnow, 1968). Because rCBF was reduced despite an increase in perfusion pressure, cerebrovascular resistance (CVR) must have been increased. When calculated from the present data, by dividing perfusion pressure by rCBF, CVR increased by $42 \%$ on changing from air equivalent to OHP, from $0.91 \pm 0.09$ to $1.29 \pm 0.23 \mathrm{mmHg} / \mathrm{ml} . / 100 \mathrm{~g} / \mathrm{min}$. This increase in CVR confirmed that the mechanism of reduction of ICP produced by OHP was direct active cerebral vasoconstriction.

The degree of reduction of ICP was compared with the reduction of $\mathrm{rCBF}$ for each run and a positive correlation found, which was just significant at the $5 \%$ level (Fig. 5).

Cerebral venous $\mathrm{PO}_{2}$ values were lower and $\mathrm{Ca}-\mathrm{vO}_{2}$ higher on both air and oxygen in the second

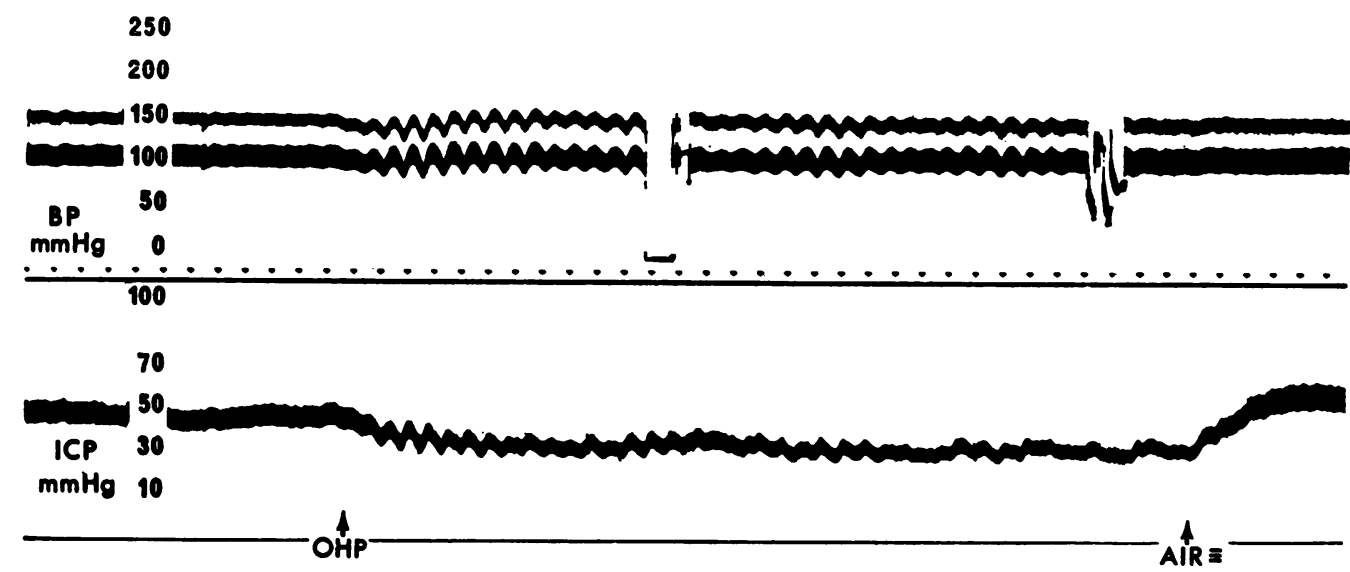

FIG. 4. Chart recording to show the effect on increased intracranial pressure of changing inspired gases from air equivalent $\left(\mathrm{O}_{2} 10 \%: \mathrm{N}_{2} 90 \%\right)$ to OHP and back to air equivalent. The time scale is in minutes. In this run there is some overshoot of intracranial pressure on resumption of air breathing. Arterial blood pressure remains stable throughout. 


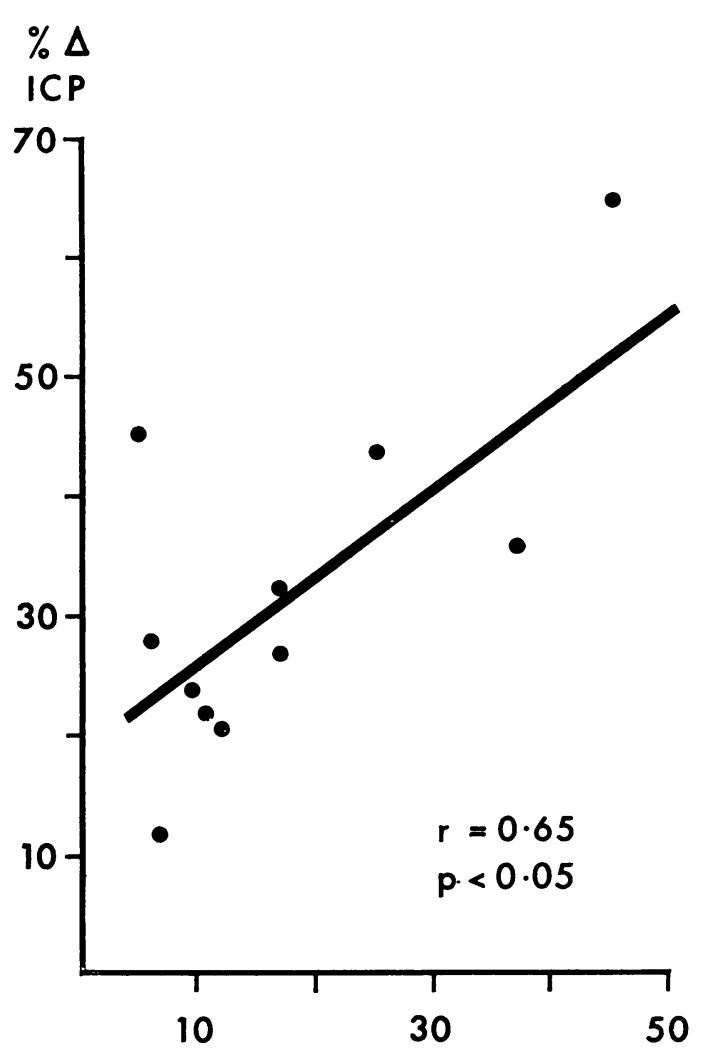

$\% \Delta \mathrm{rCBF}$

FIG. 5. Relationship between percentage change in cerebral blood flow produced by hyperbaric oxygen, and percentage change in intracranial pressure. The equation for the slope of the regression line (shown) is: $\mathrm{y}=0.73 \mathrm{x}+18 \cdot 43$.

series of dogs, possibly accounted for by the difference in placement of the sagittal sinus catheter.

\section{DISCUSSION}

CRYOGENIC BRAIN LESION The use of extreme cold to produce a focal and standardized cerebral lesion in experimental animals was first described by Hass and Taylor (1948). The method using liquid nitrogen applied to the intact dura mater through a burr hole was used by Rosomoff (1959), and the physiological and pathological sequelae have been well described by Clasen, Brown, Leavitt, and Hass (1953) and Klatzo, Piraux, and Laskowski (1958). The lesion consists of a haemorrhagic and necrotic area in the cortex and superficial white matter, with associated oedema extending deeply into white matter; ICP is almost invariably elevated after this type of lesion. In the present study, the brain was removed after the experiment, the haemorrhagic lesion excised, and the volume measured by displacement. Despite the standard method of producing the lesion, there was great variation in lesion volume, and no direct relationship between lesion size and the level of ICP.

Changes in rCBF associated with the liquid nitrogen lesion have been studied by Heipertz (1968); two Geiger-Muller tubes were placed over exposed cortex to measure the clearance of krypton85 beta radiation, in the lesion and at its periphery. Flow was reduced within the freezing lesion, but hyperaemia developed at the margins of the lesion. When this study was repeated with the skull intact, and thus in the presence of increased ICP, using gamma detection, hyperaemic flow values were no longer observed (Christ, Heipertz, Brock, and Hadjidimos, 1969). Because of the longer range of gamma activity, it is possible that in the latter study very localized areas of hyperaemia were not detected. In only two out of the seven dogs in the present study in which rCBF was measured were hyperaemic flow values recorded from the hemisphere opposite the freezing lesion. The increased flow values occurred in the dogs with the highest levels of arterial blood pressure and perfusion pressure, so that it is possible that the hyperaemia was due to loss of autoregulation. If this is so, it is of interest that these animals did respond normally to carbon dioxide and OHP. We have recently observed a similar phenomenon in baboons, which, although hyperaemic after periods of increased ICP, showed normal cerebral vasoconstriction in response to hypocapnia (Rowan, Harper, Jennett, Miller, and Tedeschi, 1970).

CHANGES IN INTRACRANIAL PRESSURE The rapidity of the fall in ICP associated with OHP suggests a vascular mechanism, and the return of ICP on cessation of OHP is equally striking. In treating head injured patients with OHP, Mogami and his colleagues (1969) observed that the ICP frequently rose above the starting pressure when OHP was discontinued. This phenomenon, shown in Fig. 4, was seldom observed in the present study, but OHP was being administered for shorter periods of time. The overshoot of pressure may be explained on the basis that OHP reduces ICP only by contracting the cerebral vascular bed, and that cerebral oedema may continue to develop, so that when cerebral vessels dilate on cessation of OHP there is less room available for expansion, and ICP must increase unless some other intracranial component can be expressed. This explanation may also account for 
the apparent diminution of effect of OHP with increasing time of exposure, seen in the present study.

Cerebral vasoconstriction can cause only a small reduction in intracranial blood volume. It is well established, however, that as the volume of any addition to the intracranial contents increases, ICP may not alter, but as the compensatory mechanisms become exhausted ICP rises with increasing severity, so that at the steep portion of the volumepressure curve, small increases in volume result in large increases in ICP; conversely, small reductions in intracranial volume may cause significant reductions in pressure (Langfitt, Weinstein, and Kassell, 1966).

CHANGES IN CEREBRAL BLOOD FLOW In deriving values for changes in total CBF from the measurement of arterial and cerebral venous $\mathrm{PO}_{2}$ several precautions have to be taken and assumptions made. Corrections should be made for temperature differences and for the blood-gas difference of the oxygen electrode for each experiment (McDowall et al, 1968). Deriving the blood oxygen saturation from $\mathrm{PO}_{2}$ using the Radiometer Blood Gas Calculator assumes that the oxygen dissociation curve for dog blood is the same as the human curve, on which the Calculator is based (Severinghaus, 1966). Bartels and Harms (1959) have shown that the curves are very similar, and this was confirmed in the present study by the close correspondence of direct and indirect measurements of oxygen saturation and content.

The extrapolation of changes in total CBF from changes in cerebral arteriovenous oxygen content difference assumes that cerebral oxygen uptake does not alter when the subject changes from air to oxygen breathing. Kety and Schmidt (1948) found no alteration in human subjects changing from air breathing to $100 \%$ oxygen at 1ATA, and Lambertsen, Kough, Cooper, Emmel, Loeschke, and Schmidt (1953) found no change with OHP at 3.5 ATA. No data on the effect of OHP on cerebral metabolic rate in conditions of raised ICP are available, but the close correspondence of the flow reductions caused by OHP in the present study, measured by both direct and indirect methods, suggests that metabolic rate did not alter significantly.

ACTION OF HYPERBARIC OXYGEN ON CEREBRAL BLOOD FLOw Controversy still exists as to the mechanism by which OHP reduces CBF. Lambertsen and his co-workers (1953) demonstrated that OHP at 3.5 ATA caused a $25 \%$ reduction in total CBF, measured by the nitrous oxide inhalation technique in normal awake man. Since there was a reduction in arterial $\mathrm{PCO}_{2}$ during $\mathrm{OHP}$ administration, the reduction in flow was ascribed to hypocapnia. In anaesthetized, ventilated dogs, Jacobson et al (1963) found that OHP at 2 ATA caused a $21 \%$ reduction in cerebral cortical blood flow, measured by krypton-85 beta clearance, despite constant arterial $\mathrm{PCO}_{2}$. The results of the present study support the concept of the latter authors that OHP can reduce CBF by direct cerebral vasoconstriction, although it is possible that brain tissue $\mathrm{PCO}_{2}$ may be a controlling factor.

Although the action of OHP was not mediated by $\stackrel{\vec{\rho}}{\rightarrow}$ arterial $\mathrm{PCO}_{2}$, it was found in this study that for OHP to be effective in reducing ICP and CBF, 을 responsiveness of the cerebral circulation to carbon dioxide had to be retained, as demonstrated by $\propto$ rising ICP and CBF when arterial $\mathrm{PCO}_{2}$ was in- \& creased. Furthermore, addition of carbon dioxide $\vec{A}$ to the inspired gases would always override the effect of OHP, causing a sharp increase in ICP while the dog continued to breathe OHP.

CEREBRAL BLOOD FLOW AND INCREASED INTRACRANIAL PRESSURE In a simple model of increased ICP, the $\omega$ cisternal perfusion preparation, $\mathrm{CBF}$ is not reduced with rising ICP until the perfusion pressure is belo $40 \mathrm{mmHg}$ in the dog (Zwetnow, Kjällquist, an Siesjö, 1968) and $35 \mathrm{mmHg}$ in the baboon (Rowaif et al, 1970). That autoregulation of CBF occurs with rising ICP was suggested by the cranirg $\mathbb{D}$ window studies of Wolff and Forbes (1928) and Fog $\mathbb{D}$ (1933). In more complex situations of increased ICP such as those produced by a space-occupying lesiod. when brain swelling and distortion are present, $\overrightarrow{0}$ less predictable relationship between ICP and CBF may be found, with considerable variation in CBF in different regions of the brain. In such circumstances any reduction of CBF may be potentially harmful. In the present study, however, there was no apparent generalized cerebral hypoxia despite the reductions in CBF, since with the marked rise in arterial $\mathrm{PO}_{2}$ there was invariably an increase in cerebral venous $\mathrm{PO}_{2}$. OHP has also been shown to increase CSF $\mathrm{PO}_{2}$ (Hollin, Espinosa, Sukoff, and Jacobson, 1968).

Cerebral vasomotor paralysis Perhaps the most important finding of this and our previous study from the standpoint of clinical application of OHP therapy was that a situation could arise with an $\bigcirc$ expanding cerebral lesion when OHP could no longer influence ICP or CBF. This state invariably 을 coexisted with complete lack of response of ICP and $D$ CBF to carbon dioxide. Unresponsiveness of cerebral vessels to carbon dioxide in adverse circumstances $\bar{N}$ was recognized in the early cranial window studies $\Omega$ (Fog, 1968). More recently, Langfitt and his $\tilde{O}$ 
colleagues $(1965 \mathrm{a} ; 1965 \mathrm{~b} ; 1966)$ showed that after ICP was considerably elevated by a supratentorial balloon and the Cushing response was failing, so that ICP approached the arterial BP, changes of arterial $\mathrm{PCO}_{2}$ no longer influenced ICP. The cerebral resistance vessels were presumed to be widely dilated and unable to respond to physiological stimuli, a state described by the phrase 'cerebral vasomotor paralysis'. Failure of cerebral vessels to dilate may be due to the fact that they are already fully dilated in a vain attempt to maintain a constant CBF, but failure to constrict, as seen in the present study, implies that vasoparalysis is present.

CLINICAL APPLICATION OF HYPERBARIC OXYGEN THERAPY From these physiological studies of the action of OHP in states of increased ICP in experimental animals, it is possible to speculate about the possible scope and limitations of OHP therapy in patients with raised ICP and brain swelling. In the patient in whom the majority of the cerebral circulation has retained its physiological integrity, OHP should produce a significant reduction of ICP without causing hypoxia despite the reduction of CBF. Because the effect of carbon dioxide at all times overrides that of OHP, the beneficial effects of OHP will be nullified by carbon dioxide retention. If generalized vasomotor paralysis is present, OHP will have no effect on ICP.

The state of generalized vasomotor paralysis represents, in clinical terms, a terminal stage, and studies in which only ICP and total CBF are monitored can detect the lack of response to carbon dioxide only at this late stage. Multichannel rCBF studies, combined with functional testing of the cerebral circulation to induced changes of arterial $\mathrm{PCO}_{2}$ and blood pressure, have recently shown that localized areas of unresponsiveness to carbon dioxide or BP alterations may be found in patients with focal cerebral ischaemia (Høedt-Rasmussen, Skinhøj, Paulson, Ewald, Bjerrum, Fahrenkrug, and Lassen, 1967; Paulson, 1968) and brain tumours (Pálvölgyi, 1969). Direct cerebral trauma also appears to cause such localized disturbances in cerebrovascular physiology (Marshall, Jackson, and Langfitt, 1969; Reivich, Marshall, and Kassell, 1969).

In addition to reducing ICP without causing cerebral hypoxia, a further theoretical beneficial effect of OHP has been suggested by clinical rCBF studies. This is the 'inverse steal phenomenon' (Lassen and Pálvölgyi, 1968) in which constriction of vessels in normal brain may increase blood flow in small unresponsive areas. Hyperventilation, with hypocapnic cerebral vasoconstriction, has been shown to reduce the size of middle cerebral artery territory infarcts in experimental animals (Soloway, Nadel, Albin, and White, 1968; Battastini, Cassachia, Bartolini, Bava, and Fieschi, 1969) and the effect attributed to the inverse steal phenomenon. Since OHP also causes vasoconstriction in normal brain, it is possible that in favourable circumstances OHP may cause inverse steal; in addition, when flow is not reduced, then oxygen delivery will be correspondingly increased. In the only reported study of this type, however, it was found that OHP at 2ATA failed to confer any additional protection to dogs subjected to middle cerebral artery ligation (Jacobson and Lawson, 1963). On the basis of the present experimental studies, the principal factor determining whether or not a patient is likely to benefit from OHP therapy appears to be the physical extent of disordered cerebrovascular function and responsiveness and, until such information is available for patients with head injuries and brain swelling, OHP therapy must be given on an empirical basis.

In 1966, Fasano et al reported on the administration of OHP at 3ATA to 25 patients, in coma after head injuries. No effect was noted in deep coma, but in the remaining patients improved responses to stimuli were found. In 66 patients with acute cerebral damage (51 traumatic) treated by Mogami et al (1969), half showed no improvement with OHP at 2ATA, 21 were greatly improved, and 12 showed some objective improvement. Improvement was found only during OHP administration; four patients actually deteriorated from their preOHP status on withdrawal of OHP, and the authors linked this with the rebound in ICP which they often observed. In most cases, ICP, measured intraventricularly, fell with OHP; the degree of reduction, and the neurological improvement, were most marked in those patients with the mildest neurological deficits. The addition of $2 \%$ carbon dioxide to the oxygen during administration of OHP always produced a marked increase in ICP, with neurological deterioration in some instances, and the authors cautioned against its use.

Using a heat-clearance probe to obtain a continuous registration of rCBF, Wüllenweber, Gott, and Holbach (1969) observed an increase in flow in patients with head injuries treated with OHP. This interesting finding may be explained in either of two possible ways. If the probe was measuring flow in area of damaged brain, the increase in flow could have represented an inverse steal phenomenon, due to vasoconstriction elsewhere. Alternatively, if the area of brain under the probe had lost its powers of autoregulation, the increase of flow may have been due to an increase of perfusion pressure, caused not by an increase of blood pressure but by a 
decrease in ICP, consequent on vasoconstriction elsewhere in the brain. This argument leads to the speculation that the inverse steal phenomenon may be due to increase in perfusion pressure combined with loss of autoregulation, rather than to redistribution of flow.

The results of the clinical studies appear to confirm in large part the predictions based on the animal studies reported here. Further development of OHP as a therapeutic technique must therefore depend on knowledge of the disorders of cerebrovascular function which follow cerebral trauma, hypoxia, and ischaemia.

\section{REFERENCES}

Bartels, H., and Harms, H. (1959). Sauerstoffdissoziationskurven des Blutes von Säugetieren. Pflügers Arch. ges. Physiol., 268, 334-365.

Battastini, N., Cassachia, M., Bartolini, A., Bava, G., and Fieschi, C. (1969). Effects of hyperventilation on focal brain damage following middle cerebral artery occlusion. In Cerebral Blood Flow, Pp. 249-253. Edited by M. Brock, C. Fieschi, D. H. Ingvar, N. A. Lassen, and K. Schürmann. Springer: Berlin.

Betz, E., Ingvar, D. H., Lassen, N. A., and Schmahl, F. W. (1966). Regional blood flow in the cerebral cortex, measured simultaneously by heat and inert gas clearance. Acta physiol. scand., 67, 1-9.

Christ, R., Heipertz, R., Brock, M., and Hadjidimos, A. A. (1969). The effect of intracranial pressure on perifocal hyperemia. In Cerebral Blood Flow, pp. 184-186. Edited by M. Brock, C. Fieschi, D. H. Ingvar, N. A. Lassen, and K. Schürmann. Springer: Berlin.

Clasen, R. A., Brown, D. L., Leavitt, S., and Hass, G. M. (1953). The production by liquid nitrogen of acute closed cerebral lesions. Surg. Gynec. Obstet., 96, 605-616.

Coe, J. E., and Hayes, T. M. (1966). Treatment of experimental brain injury by hyperbaric oxygenation. Amer. Surg., 32, 493-495.

Dunn, J. E., and Connolly, J. M. (1966). Effects of hypobaric and hyperbaric oxygen on experimental brain injury. In Proceedings of the 3rd International Conference on Hyperbaric Medicine, pp. 447-454. Edited by I. W. Brown, and B. G. Cox. National Academy of Science: Washington.

Fasano, V. A., Broggi, G., Urciuoli, R., DeNunno, T., and Lombard, G. F. (1966). Clinical applications of hyperbaric oxygen in traumatic coma. In Proceedings of the $3 \mathrm{rd}$ International Congress of Neurological Surgery. Edited by A. C. de Wets. Excerpta med. (Amst.), 110, 502-505.

Fog, M. (1933). Influence of intracranial hypertension upon the cerebral circulation. Acta psychiat. scand., 8, 191-198.

Fog, M. (1968). Autoregulation of cerebral blood flow and its abolition by local hypoxia and/or trauma. Scand. J. clin. Lab. Invest., Suppl. 102, VB.

Glass, H. I., and Harper, A. M. (1962). The measurement of the partition coefficient of Krypton between brain cortex and blood by a double isotope method. Phys. in Med. Biol., 7, 335-339.

Harper, A. M., Glass, H. I., and Glover, M. M. (1961). Measurement of blood flow in the cerebral cortex of dogs by the clearance of Krypton-85. Scot. med. J., 6, 12-17.

Hass, G. M., and Taylor, C. B. (1948). A quantitative hypothermal method for the production of local injury of tissue. Arch. Path., 45, 563-580.

Hayman, A., Saltzman, H. A., and Whalen, R. E. (1966).
Use of hyperbaric oxygenation in the treatment of cerebra ischaemia and infarction. Circulation, Suppl. 2, 33, 20.

Heipertz, R. (1968). The effects of local cortical freezing on rCBF in the cat. Scand. J. clin. Lab. Invest., Suppl. 102@ XIVD.

Høedt-Rasmussen, K., Skinhøj, E., Paulson, O., Ewald, J. Bjerrum, J. K., Fahrenkrug, A., and Lassen, N. A. (1967) (S) Regional cerebral blood flow in acute apoplexy. Arch Neurol. (Chic.), 17, 271-281.

Hollin, S. A., Espinosa, O. E., Sukoff, M. H., and Jacobson J. H. (1968). The effect of hyperbaric oxygenation on cerebrospinal fluid oxygen. J. Neurosurg., 29, 229-235.

Jacobson, I., Harper, A. M., and McDowall, D. G. (1963) The effects of oxygen under pressure on cerebral bloodflow and cerebral venous oxygen tension. Lancet, 2 549.

Jacobson, I., and Lawson, D. D. (1963). The effect of hyper baric oxygen on experimental cerebral infarction in the dog. J. Neurosurg., 20, 849-859.

Kety, S. S., and Schmidt, C. F. (1948). The effects of altered arterial tensions of carbon dioxide and oxygen oncerebral blood flow and cerebral oxygen consumption of normal young men. $J$. clin. Invest., 27, 484-492.

Klatzo, I., Piraux, A., and Laskowski, E. J. (1958). The ralationship between edema, blood-brain-barrier and tissue

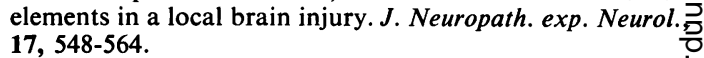

Lambertsen, C. J., Kough, R. H., Cooper, D. Y., Emmel w G. L., Loeschke, H. H., and Schmidt, C. F. (1953) Oxygen toxicity: effects in man of oxygen inhalation 1 and 3.5 atmospheres upon blood gas transport, cerebtalf

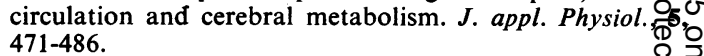

Langfitt, T. W., Kassell, N. F., and Weinstein, J. D. (196亩) Cerebral blood flow with intracranial hypertension. Neurolcgy (Minneap.), 15, 761-773.

Langfitt : T. W., Weinstein, J. D., and Kassell, N. F. (1965b) Cerebral vasomotor paralysis produced by intracrapis hypertension. Neurology (Minneap.), 15, 622-641.

Langfitt, T. W., Weinstein, J. D., and Kassell, N. F. (19ळ). Vascular factors in head injury. In Head Injury, 172-194. Edited by W. F. Caveness and A. E. Walker. Lippincott: Philadelphia.

Lassen, N. A., and Ingvar, D. H. (1961). The blood flow of the cerebral cortex determined by radioactive Krypton-85. Experientia (Basel), 17, 42-43.

Lassen, N. A., and Pálvölgyi, R. (1968). Cerebral stea during hypercapnia and the inverse reaction duringo hypocapnia observed by the 133-Xenon technique in man Scand. J. clin. Lab. Invest., Suppl. 102, XIIID.

McDowall, D. G., Ledingham, I. McA., and Tindal, s. (1968). Alveolar-arterial gradients for oxygen at 1, 2 and 3 3 atmospheres absolute. J. appl. Physiol., 24, 324-329.

Marshall, W. J. S., Jackson, J. L. F., and Langfitt, T. W (1969). Brain swelling caused by trauma and arterialhypertension. Arch. Neurol. (Chic.), 21, 545-553.

Miller, J. D., Fitch, W., and Cameron, B. D. (1969) Regional cerebral blood flow measurement in the presence; of raised intracranial pressure. A comparison between 3 thermal and Krypton 85 beta clearance. J. surg. Res., 9 399-407.

Miller, J. D., Fitch, W., Ledingham, I. McA., and Jennett, W. B. (1970). The effect of hyperbaric oxygen on increased
intracranial pressure. J. Neurosurg., 33, 287-296.

Moody, R. A., Mead, C. O., Ruamsuke, S., and Mullan, SD (1970). Therapeutic value of oxygen at normal and hyper baric pressure in experimental head injury. J. Neurosurg. 32, $51-54$.

Mogami, H., Hayakawa, T., Kanai, N., Kuroda, R. Yamada, R., Ikeda, T., Katsurada, K., and Sugimoto, T. 
(1969). Clinical application of hyperbaric oxygenation in the treatment of acute cerebral damage. J. Neurosurg., 31, 636-643.

Pálvölgyi, R. (1969). Regional cerebral blood flow in patients with intracranial tumours. J. Neurosurg., 31, 149-163.

Paulson, O. B. (1968). Regional cerebral blood flow in middle cerebral artery occlusion. Scand. J. clin. Lab. Invest., Suppl. 102, XVIC.

Reivich, M., Marshall, W. J. S., and Kassell, N. F. (1969). Loss of autoregulation produced by cerebral trauma. In Cerebral Blood Flow, pp. 205-208. Edited by M. Brock, C. Fieschi, D. H. Ingvar, N. A. Lassen, and K. Schürmann. Springer: Berlin.

Rosomoff, H. L. (1959). Experimental brain injury during hypothermia. J. Neurosurg., 16, 177-187.

Rowan, J. O., Harper, A. M., Miller, J. D., Tedeschi, G. M., and Jennett, W. B. (1970). Relationship between volume flow and velocity in the cerebral circulation. J. Neurol. Neurosurg. Psychiat., 33, 733-738.

Severinghaus, J. W. (1966). Blood gas calculator. J. appl. Physiol., 21, 1108-1116.

Soloway, M., Nadel, W., Albin, M. S., and White, R. J. (1968). The effect of hyperventilation on subsequent cerebral infarction. Anesthesiology, 29, 975-980.
Sukoff, M. H., Hollin, S. A., Espinosa, O. E., and Jacobson, J. H. (1968). The protective effect of hyperbaric oxygenation in experimental cerebral edema. J. Neurosurg., 29, 236-241.

Wolff, H. G., and Forbes, H. S. (1928). The cerebral circulation. V. Observations of the pial circulation during changes in intracranial pressure. Arch. Neurol. Psychiat. (Chic.), 20, 1035-1047.

Wüllenweber, R., Gött, U., and Holbach, K. H. (1969). rCBF during hyperbaric oxygenation. In Cerebral Blood Flow, pp. 271-272. Edited by M. Brock, C. Fieschi, D. H. Ingvar, N. A. Lassen, and K. Schürmann. Springer: Berlin.

Zierler, K. L. (1965). Equations for measuring blood flow by external monitoring of radioisotopes. Circulat. Res., 16, 309-321.

Zwetnow, N. (1968). CBF autoregulation to blood pressure and intracranial pressure variations. Scand. J. clin. Lab. Invest., Suppl. 102, VA.

Zwetnow, N., Kjällquist, A., and Siesjö, B. K. (1968). Cerebral blood flow during intracranial hypertension related to tissue hypoxia and to acidosis in cerebral extracellular fluids. In Cerebral Circulation (Progress in Brain Research, vol. 30), Pp. 87-92. Edited by W. Luyendyk. Elsevier: Amsterdam. 